\title{
Surgical Management of Cardiopericardial Hydatid Disease: A Tunisian Center Experience
}

Ben Jmaa Hela ${ }^{1 *}$, Bouassida Abir ${ }^{1}$, Triki Faten ${ }^{2}$, Dammak Aiman ${ }^{1}$, Hentati Abdessalem ${ }^{1}$, Ben Jmaa Tarak ${ }^{3}$, Souissi Iheb ${ }^{4}$, Masmoudi Sayda ${ }^{1}$, Elleuch Nizar ${ }^{1}$, Kammoun Samir ${ }^{2}$, Ben Jmaa Mounir ${ }^{3}$, Karoui Abdelhamid ${ }^{4}$ and Frikha Imed ${ }^{1}$

${ }^{1}$ Department of Cardiovascular and Thoracic Surgery, Habib Bourguiba Hospital, Sfax, Tunisia

${ }^{2}$ Department of Cardiology, Hedi Chaker Hospital, Sfax, Tunisia

${ }^{3}$ Department of Infectious Diseases, Hedi Chaker Hospital, Sfax, Tunisia

${ }^{4}$ Department of Anesthesiology, Habib Bourguiba Hospital, Sfax, Tunisia

"Corresponding author: Ben Jmaa Hela, Department of Cardiovascular and Thoracic Surgery, Habib Bourguiba Hospital, Sfax 3029, Tunisia, Tel: 0021696704740; Email: helabenjemaa2015@gmail.com

Received date: November 9, 2015, Accepted date: November 18, 2015, Published date: November 19, 2015

Copyright: @ 2015 Hela, et al. This is an open-access article distributed under the terms of the Creative Commons Attribution License, which permits unrestricted use, distribution and reproduction in any medium, provided the original author and source are credited.

\section{Abstract}

Introduction: Cardiac hydatid disease is a rare, but it is potentially a life-threatening pathology. It has fatal complications such as valvular dysfunction, free wall rupture, embolism, anaphylactic reactions, conduction disturbances, or congestive heart failure.

Methods: We report 12 cases of cardiopericardial hydatid disease that underwent operation in our institution between January 1998 and December 2014, and we review our results. The mean age was 31.83 years and it ranges of 11 to 65 years. Male to female ratio was 1 .

The diagnosis of hydatid disease was confirmed by transthoracic echocardiography in all patients. The cyst was located in the left ventricular free wall in 5 cases, the right ventricular free wall in 1 case, the interventricular septum in 3 cases, the interatrial septum in 2 cases, and the pericardium in 1 case.

Three patients had multiple organ hydatidosis: in the interatrial septum and the two lungs in one case; in the left ventricle, the left lung, the liver, and the peritoneum in 1 case; and in the left ventricle, the left lung, the liver and the breasts in 1 case.

All of our patients underwent surgery. The patients with cardiac cysts were operated under sternotomy and standard cardiopulmonary bypass with antegrade cardioplegia and aortic cross-clamping.

The patient with pericardial hydatidosis was operated under posterolateral thoracotomy and without cardiopulmonary bypass.

Results: The postoperative period was uneventful in all our patients. We didn't have any cardiac hydatidosis recurrence in the follow-up of our patients. Only one patient was operated two years after cardiac surgery for recurrence of pulmonary cysts.

Conclusion: Surgery should be recommended in all cases of cardiopericardial hydatid disease in order to avoid their complications.

\section{Keywords: Cysts; Hydatidosis; Heart; Pericardium; Methods}

Echocardiography; Surgery

\section{Introduction}

Hydatid disease is a parasitic infection caused by the development of the larval form of the Teania of Echinococcus granulosus.

This disease is endemic and constitutes a significant public health problem in the Mediterranean countries including Tunisia [1].

We aimed to report our experience, review epidemiological characteristics and surgical treatment of cardiopericardial hydatidosis, and to determine our short and long-term outcomes.
We reviewed all patients who underwent surgery for cardiopericardial hydatid cyst in our institution during the period between January 1998 and December 2014. The number of patients was twelve: 6 male and 6 female. The mean age was 31.83 years with a range between 11 to 65 years.

Diagnosis was fortuitous in 5 cases; and it was revealed by dyspnea and chest pain in 5 cases. Complications were revealing in 2 cases: a pulmonary embolism in 1 case and a lower limb ischemia in 1 case.

Physical examination was normal in 10 patients. It found a pulmonary edema in 1 patient, and a lower limb ischemia in 1 patient. 
Citation: Jmaa Hela B, Abir B, Faten T, Aiman D, Abdessalem H, et al. (2015) Surgical Management of Cardiopericardial Hydatid Disease: A

All the patients underwent transthoracic echocardiography which revealed the cystic mass and its localization.

Pericardium was involved in 1 case, left ventricle in 5 cases, right ventricle in 1 case, interatrial septum in 2 cases, and the interventricular septum in 3 cases. Eleven patients underwent surgery through a median sternotomy and cardiopulmonary bypass. The patient with pericardial location was operated under posterolateral thoracotomy.

The surroundings of the cysts were wrapped to prevent their contamination. The left and right ventricle free wall cysts were opened and germinative membranes were removed. Then, a capitonage was performed, and the cavity was closed with multiple sutures.

The patients with interventricular septum cyst underwent excision of the cystic mass through a right atriotomy in 2 cases, and through a ventriculotomy in 1 case. Then, the septum was repaired by a direct suture in 2 cases, and by a synthetic patch in 1 case (Figure 1 ).

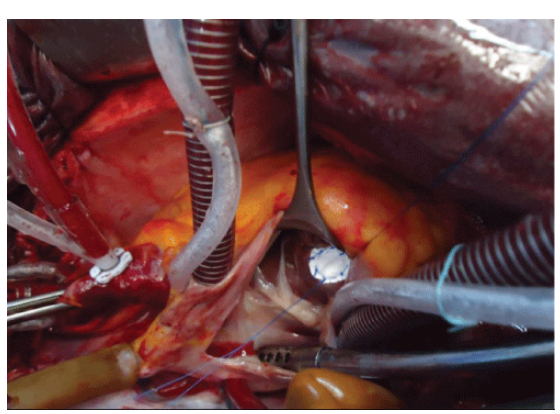

Figure 1: Suture of the septal defect by a synthetic patch.

The patient with a pericardial cyst underwent a cystectomy under a posterolateral thoracotomy without cardiopulmonary bypass.

The patients with interatrial septum cyst were accessed by a right atriotomy (Figures 2 and 3). After cystic resection, the interatrial septum was repaired by a direct suture in the two cases.

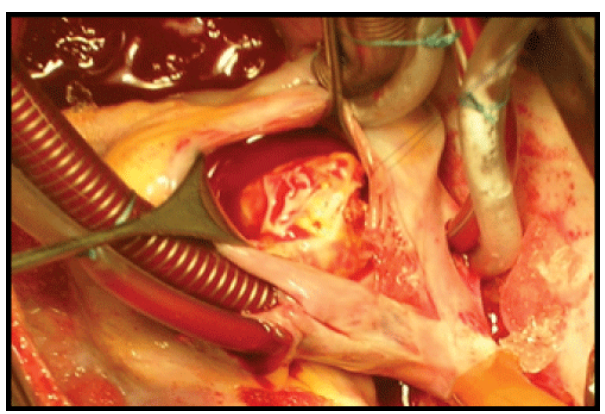

Figure 2: Intraoperative view showing a cyst of the interatrial septum through a right atriotomy (arrow).

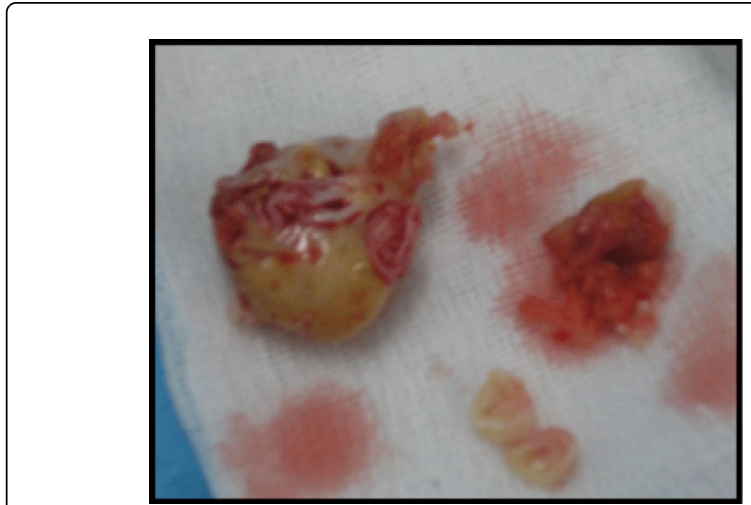

Figure 3: Macroscopic aspect of the cyst.

Three patients had multi-organ hydatidosis involving the heart: in the interatrial septum and the two lungs in one case; in the inferior wall of the left ventricle, the left lung, the liver, and the two breasts in one case (Figures 4 and 5); and in the left ventricle, the left lung, the liver, and the peritoneum in one case (Figures 6 and 7).

The hydatid location in the heart, the lungs, and the breasts were operated in a single session under sternotomy.

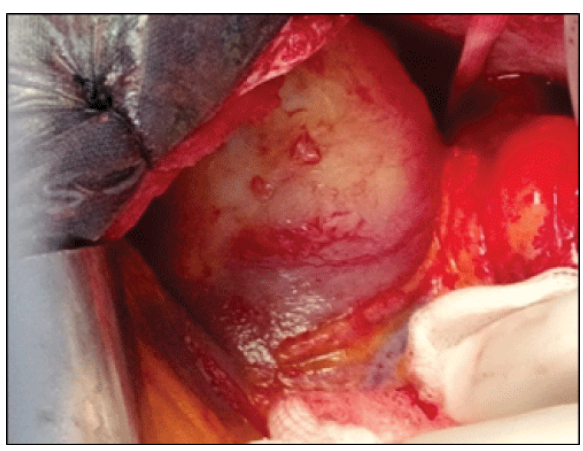

Figure 4: Intraoperative view of the left ventricular cyst protruding into the pericardium (arrow).

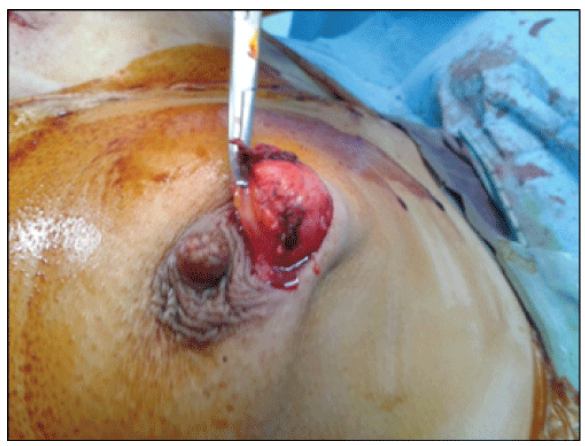

Figure 5: Intraoperative view of a removal of hydatid cyst from the breast. 


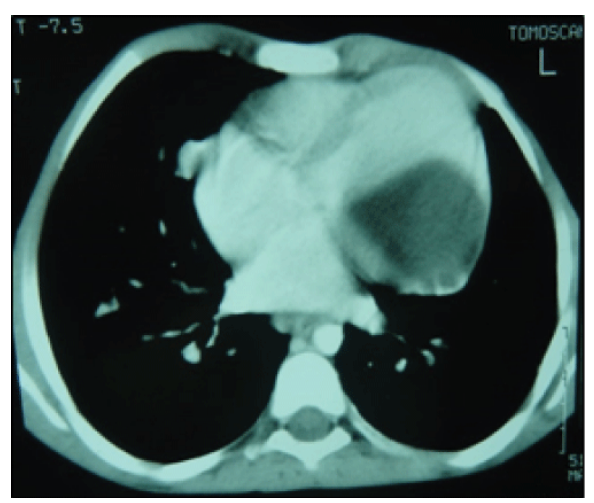

Figure 6: thoracic CT scan revealing a hypodense mass in the left ventricle (arrow).

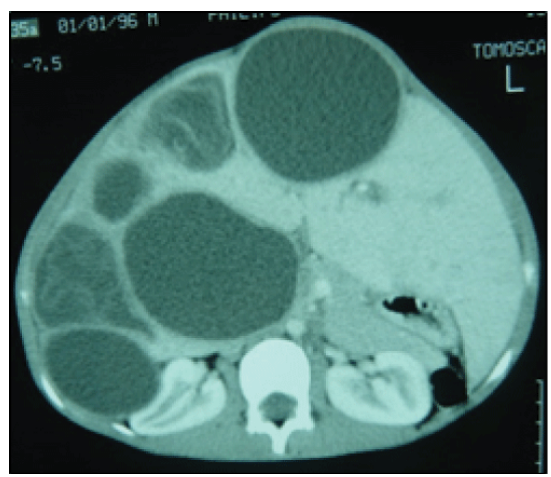

Figure 7: Abdominal CT scan showing cysts in the liver and the peritoneum.

\section{Results}

Albendazole was used in the postoperative period in all patients and carried out for 6 months. The postoperative period was uneventful in all our patients and they were discharged from hospital without complications.

During this follow-up period, an echocardiography was performed yearly in each patient. The average duration of follow-up was 99.45 months, and it ranges from 21 to 213 months.

We did not observe any late cardiac problems or recurrence of the cardiac cysts. One patient was operated two years later under thoracotomy for recurrence of right pulmonary cysts. Results are shown in Table 1.

\section{Discussion}

Echinococcosis is a tissue parasitic infestation that leads to a significant health problem in undeveloped and developing countries [2]. It is common in several regions of the world, for example, the Mediterranean countries, the Middle East, South America, and East Africa [3].
In human beings, it is caused by the larva of Echinococcus granulosus. The sheep is the intermediate host and the dog is the definitive host, but man is a common accidental host [4].

The liver and the lungs are the most common sites of infection [5]. Cardiac echinococcosis is not frequent, accounting for only $0.5 \%$ to $2 \%$ of all hydatid infestations [2,6]. The left ventricle is involved most frequently (55-60\%) [4]. The right ventricle is involved in $10-15 \%$ of all cardiac cysts [7].

Involvement of the interventricular septum is reported in $5-9 \%$ of cardiac cases [4]. Distribution in the left atrium occurs in $8 \%$ of cardiac cases [2]. The interatrial septum is involved in $2 \%$ of cases [8]. The first case reported in the literature was in 1964 [9]. Then, a few cases were reported [10].

In our series, the left ventricle was the most-involved ( 5 cases). We reported also three cases located in the interventricular septum, two cases in the interatrial septum, and one case in the right ventricle.

Isolated pericardial location without cardiac involvement is exceptional [11]. This location was observed in only one of our patients.

Valvular cysts are unusual. Sensoz Y et al. reported a case of a hydatid cyst located in the right ventricle involving the posterior papillary muscle requiring tricuspid valve excision and its replacement with a bioprosthesis [6].

Aksakal E et al. presented the first case of congestive heart failure and mitral stenosis because of the involvement of the posterior mitral leaflet by a hydatid cyst measuring $2.7^{\star} 2.2 \mathrm{~cm}$ [12].

Multivisceral echinococcosis with cardiac involvement is exceptional [13]. We reported three cases of multi-organ involvement, in which the cardiac and the pulmonary location were operated in a single session via a sternotomy. Bilateral cysts of the breasts were also resected in the same operation in one patient.

Clinical signs and symptoms vary according to the number, the size, and the site of the cysts [10]. They are usually asymptomatic. Chest pain, palpitations, and dyspnea may be revealing symptoms.

Five of our patients were asymptomatic and the diagnosis was fortuitous after chest radiography. Five patients had dyspnea and thoracic pain.

Cardiovascular complications are arrhythmia, valvular dysfunction, heart failure, pulmonary or systemic embolism, pulmonary hypertension, and anaphylactic reactions [4]. These complications can lead to sudden death. Rupture is also a life-threatening complication of cardiac hydatid cyst. It is usually intracavitary in the right-sided cysts, and intrapericardial in the left-sided cysts.

In our series, we observed one case of pulmonary embolism complicating an interatrial septum cyst, and one case of lower limb ischemia by embolism into the femoral artery.

Echocardiography, computerized tomography, and magnetic resonance imaging are valuable non-invasive diagnostic tools for cardiac hydatid disease [14]. Serologic tests are also a helpful supplement.

The diagnosis was made by trans-thoracic echocardiography in all our patients. Due to these fatal consequences, it should be treated by surgical excision under cardiopulmonary bypass as soon as it is diagnosed, even in asymptomatic patients $[6,8,15,16]$. It is important 
Page 4 of 5

to consider the location, the number and the size of the cysts when choosing the surgical approach which must be performed carefully, given the risk of embolism and anaphylaxis that surgery may bring $[3,10]$.

In case of involvement of the heart and the lungs, cardiac and lung hydatid cyst one-stage operation has a lot of advantages: the period of rehabilitation and, as well as the overall treatment costs and the hospital stay, are considerably reduced [17]. Median sternotomy is suitable for this treatment because it offers an excellent access to the heart and the lungs, with less postoperative pain than thoracotomy [17]. That's why we opted for combined surgery through sternotomy in our three patients with multiorgan involvement.
Neoadjuvant and medical treatment with albendazole, allows preoperative sterilization of the cyst and a lower risk of intraoperative dissemination. Some authors have suggested that postoperative treatment also allows a reduction of recurrences [18]. We also used albendazole in all of our patients in pre and postoperative period for 6 months.

In the long-term echocardiographic controls, we did not observe any recurrence in the cardiac location. Only one patient was reoperated under thoracotomy for recurrence in the pulmonary location.

\begin{tabular}{|c|c|c|c|c|c|}
\hline Case & Cyst localization & Surgical approach & Operation & Short term result & Long term result \\
\hline 1 & Left ventricle wall & Left ventriculotomy & $\begin{array}{l}\text { Cystectomy-capitonage and } \\
\text { suture of the ventriculotomy }\end{array}$ & Uneventful & No hydatid recurrence \\
\hline 2 & Interatrial septum and lungs & Right atriotomy & $\begin{array}{l}\text { Cystectomy, suture of the } \\
\text { interatrial septum and } \\
\text { resection of the pulmonary } \\
\text { cysts }\end{array}$ & Uneventful & $\begin{array}{l}\text { Recurrence of the pulmonary } \\
\text { cysts }\end{array}$ \\
\hline 3 & $\begin{array}{l}\text { Left ventricle wall, left lung, } \\
\text { liver and peritoneum }\end{array}$ & Left ventriculotomy & $\begin{array}{l}\text { Cystectomy-capitonage and } \\
\text { suture of the ventriculotomy } \\
\text { and resection of the } \\
\text { pulmonary cysts }\end{array}$ & Uneventful & No hydatid recurrence \\
\hline 4 & Left ventricle wall & Left ventriculotomy & $\begin{array}{l}\text { Cystectomy-capitonage and } \\
\text { suture of the ventriculotomy }\end{array}$ & Uneventful & No hydatid recurrence \\
\hline 5 & Pericardium & $\begin{array}{l}\text { Thoracotomy and } \\
\text { pericardotomy }\end{array}$ & $\begin{array}{l}\text { Cystectomy and partial } \\
\text { pericardectomy }\end{array}$ & Uneventful & No hydatid recurrence \\
\hline 6 & Right ventricle wall & Right ventriculotomy & $\begin{array}{l}\text { Cystectomy-capitonage and } \\
\text { suture of the ventriculotomy }\end{array}$ & Uneventful & No hydatid recurrence \\
\hline 7 & Left ventricle wall & Left ventriculotomy & $\begin{array}{l}\text { Cystectomy-capitonage and } \\
\text { suture of the ventriculotomy }\end{array}$ & Uneventful & No hydatid recurrence \\
\hline 8 & Inter-ventricular septum & Right ventriculotomy & $\begin{array}{l}\text { Cystectomy and suture of } \\
\text { the inter-ventricular septum }\end{array}$ & Uneventful & No hydatid recurrence \\
\hline 9 & Inter-ventricular septum & Right atriotomy & $\begin{array}{l}\text { Cystectomy and suture of } \\
\text { the inter-ventricular septum }\end{array}$ & Uneventful & No hydatid recurrence \\
\hline 10 & $\begin{array}{l}\text { Left ventricle wall, left lung, } \\
\text { liver, and breasts }\end{array}$ & Left ventriculotomy & $\begin{array}{l}\text { Cystectomy-capitonage and } \\
\text { suture of the ventriculotomy } \\
\text { and resection of the } \\
\text { pulmonary and the breasts } \\
\text { cysts }\end{array}$ & Uneventful & No hydatid recurrence \\
\hline 11 & Inter-ventricular septum & Right atriotomy & $\begin{array}{l}\text { Cystectomy and suture of } \\
\text { the septal defect by a } \\
\text { synthetic patch }\end{array}$ & Uneventful & No hydatid recurrence \\
\hline 12 & Inter-atrial septum & Right atriotomy & $\begin{array}{l}\text { Cystectomy and suture of } \\
\text { the inter-atrial septum }\end{array}$ & Uneventful & No hydatid recurrence \\
\hline
\end{tabular}

Table 1: Analysis of cardio-pericardial hydatid cyst cases.

\section{Conclusion}

Cardiac hydatid cysts are rare. They are usually asymptomatic for a long period. So, they must be kept in mind in patients in endemic countries.

Surgical treatment is necessary as soon as the diagnosis is established because there is a risk for rupture, dissemination to the adjacent tissue, embolism, or anaphylactic shock [6].

\section{References}

1. Guven A, Sokmen G, Yuksel M, Kokoglu OF, Koksal N, et al. (2004) A case of asymptomatic cardiopericardial hydatid cyst. Jpn Heart J 45: 541-545.

2. Tetik O, Yetkin U, Yazici M, Tulukoglu E, Gurbuz A (2004) A case with giant hydatid cyst localized in right ventricle wall. Turkish J Thorac Cardiovasc Surg 12: 265-267. 
Citation: Jmaa Hela B, Abir B, Faten T, Aiman D, Abdessalem H, et al. (2015) Surgical Management of Cardiopericardial Hydatid Disease: A Tunisian Center Experience. Trop Med Surg 3: 200. doi:10.4172/2329-9088.1000200

Page 5 of 5

3. Sirlak M, Ozcinar E, Eren NT, Eryilmaz S, Uysalel A, et al. (2009) Multiple hydatid cystectomy of the heart necessitating LIMA to LAD anastomosis in a young patient. Cardiovasc Pathol 18: 53-56.

4. Besir Y, Gucu A, Surer S, Rodoplu O, Melek M, et al. (2013) Giant cardiac hydatid cyst in the interventricular septum protruding to right ventricular epicardium. Indian heart journal 65: 81-83.

5. Gürgün C, Nalbantgil S, Cinar CS (2001) Two cases of cardiac cyst hydatid with right and left ventricular involvement. Int J Cardiol 78: 193-195.

6. Sensoz Y, Ozkokeli M, Ates M, Akcar M (2005) Right ventricle hydatid cyst requiring tricuspid valve excision. Int J Cardiol 101: 339-341.

7. Bréchignac X, Durieu I, Perinetti M, Gérinière L, Richalet C, et al. (1997) [Hydatid cyst of the heart]. Presse Med 26: 663-665.

8. Yaliniz H, Tokcan A, Salih OK, Ulus T (2006) Surgical treatment of cardiac hydatid disease: A report of 7 cases. Tex Heart Inst J 33: 333-339.

9. Minetto E, Prinotti C, Purini T (1964) Sudden Death Due to Primary Echinococcosis of the Interatrial Septum. Clinical and Medico-Legal Interest. Minerva Medicoleg 84: 189-194.

10. Tuncer E, Tas SG, Mataraci I, Tuncer A, Donmez AA, et al. (2010) Surgical treatment of cardiac hydatid disease in 13 patients. Tex Heart Inst J 37: 189-193.

11. Elkarimi S, Ouldelgadia N, Gacem H, Zouizra Z, Boumzebra D, et al. (2014) [Tamponade reveals an intra-pericardial hydatid cyst - a case report]. Ann Cardiol Angeiol (Paris) 63: 267-270.
12. Aksakal E, Degirmenci H, Bakirci E M (2010) A case of mitral valve involvement by hydatid cyst disease. International Journal of Cardiology 140: Supplement 1 S1-S93.

13. Grozavu C, Ilias M, Pantile D (2014) Multivisceral echinococcosis: concept, diagnosis, management. Chirurgia (Bucur) 109: 758-768.

14. Kaplan M, Demirtas M, Cimen S, Ozler A (2001) Cardiac hydatid cysts with intracavitary expansion. Ann Thorac Surg 71: 1587-1590.

15. Salih OK, Celik SK, TopcuoÄŸlu MS, KisacikoÄŸlu B, Tokcan A (1998) Surgical treatment of hydatid cysts of the heart: a report of 3 cases and a review of the literature. Can J Surg 41: 321-327.

16. Kelle S, Kohler U, Thouet T, Fleck E, Nagel E. Cardiac involvement of Echinococcus granulosus evaluated by multi-contrast CMR imaging. Int J Cardiol Jan 9 2009; 131 (2): 59-60.

17. Atalay A, Salih OK, Gezer S, Gocena U, Yaliniz H, et al. (2013) Simultaneous heart and bilateral lung hydatid cyst operated in a single session. Heart Lung Circ 22: 682-684.

18. Henaine R, Mathevet JL, Rouvière H, Di-Filippo S, Cannesson M, et al. (2008) Coronary artery bypass in myocardial ischemia of the young due to hydatid cyst. J Card Surg 23: 573-575. 